\title{
Karyomegalic interstitial nephritis
}

INSERM

\section{Source}

INSERM. (1999). Orphanet: an online rare disease and orphan drug data base.

Karyomegalic interstitial nephritis. ORPHA:401996

Karyomegalic interstitial nephritis is a rare, genetic renal disease characterized by slowly progressive, chronic, tubulointerstitial nephritis, leading to end-stage renal disease before the age of 50 years, manifesting with mild proteinuria, glucosuria and, occasionally, urinary sediment abnormalities (mainly hematuria). Mild extrarenal manifestations, such as recurrent upper respiratory tract infections and abnormal liver function tests, may be associated. Renal biopsy reveals severe, chronic, interstitial fibrosis and tubular changes, as well as hallmark karyomegalic tubular epithelial cells which line the proximal and distal tubules and have enlarged, hyperchromatic nuclei. 